Check for updates

Cite this: RSC Adv., 2021, 11, 4873

Received 27th October 2020

Accepted 14th January 2021

DOI: 10.1039/d0ra09152a

rsc.li/rsc-advances

\section{Robust immobilization of anionic silver nanoparticles on cellulose filter paper toward a low-cost point-of-use water disinfection system with improved anti-biofouling properties $\dagger$}

\author{
Gongyan Liu, ${ }^{\mathrm{abc}}$ Ruiquan Yu, ${ }^{\mathrm{abc}}$ Jing Jiang, ${ }^{a}$ Zhuang Ding, ${ }^{\mathrm{b}}$ Jing $\mathrm{Ma}^{\mathrm{c}}$ \\ and Ruifeng Liang (D) $* d$
}

Silver nanoparticle (AgNP)-decorated cellulose filter paper (FP), a low-cost point-of-use (POU) water disinfection system, can supply affordable and safe drinking water for people in desperate need, especially in rural areas in developing countries. However, owing to the unstable immobilization of AgNPs, silver can leach into the treated drinking water from the FP and exceed the World Health Organization (WHO) drinking water limit $\left(<100 \mu \mathrm{g} \mathrm{L}^{-1}\right)$, which is a potential threat to both human health and the environment. In this work, in order to robustly immobilize anionic silver nanoparticles (GA@AgNPs), we facilely prepared lipoic acid-modified cellulose filter paper (LA-FP), in which GA@AgNPs were robustly immobilized onto filter paper (GA@AgNPs-LA-FP) by strong chelation via the disulfide bond of LA with the surface of the silver nanoparticles. GA@AgNPs-LA-FP exhibited both excellent bacterial anti-adhesion activity and strong bactericidal activity, which can synergistically mitigate biofouling by inhibiting biofilm formation on the paper surface. Moreover, employed as a gravity-driven bactericidal filter, the GA@AgNPs-LA-FP membrane treated $100 \mathrm{~mL}$ of river water within $10 \mathrm{~min}$, and the resulting water quality met the WHO drinking water standards, indicating this material's practical application for POU water disinfection.

\section{Introduction}

A clean and safe drinking water supply is a cornerstone for human life. ${ }^{1-3}$ However, acute waterborne illnesses caused by pathogens in drinking water are still serious threats to human health, especially in rural areas in developing countries. ${ }^{4-6}$ Currently, over two million deaths a year, mostly of children, are caused by waterborne illnesses such as diarrhea, vomiting, and gastroenteritis. ${ }^{7,8}$ Therefore, point-of-use (POU) technologies

${ }^{a}$ College of Biomass Science and Engineering, Sichuan University, Chengdu 610065, China.E-mail: lrfcy@163.com

${ }^{b}$ National Engineering Research Center of Clean Technology in Leather Industry, Sichuan University, Chengdu 610065, China

${ }^{c}$ The Key Laboratory of Leather Chemistry and Engineering of Ministry of Education, Sichuan University, Chengdu 610065, China

${ }^{d}$ The State Key Laboratory of Hydraulic and Mountain River Engineering, Sichuan University, Chengdu 610065, China

$\dagger$ Electronic supplementary information (ESI) available: Schematic illustration of the synthetic route of GA@AgNPs; HRTEM image of GA@AgNPs; zeta potential of GA@AgNPs at different pH values; and particle size histograms of GA@AgNPs. Ag 3d core-level XPS spectra of the GA@AgNPs-LA-FP. ATR-FTIR spectra of pristine FP, LA-FP and GA@AgNPs-LA-FP. The cytotoxicity of GA@AgNPs-LA-FP. CLSM images of biofilm structures developed on FP and GA@AgNPs-LA-FP. Bactericidal stability test of the GA@AgNPs-LA-FP. See DOI: 10.1039/d0ra09152a that can reduce pathogens in water sources have been recommended as effective solutions to provide safe drinking water., ${ }^{9,10}$

Since the early twentieth century, filtration technologies capable of removing colloids, suspended solids, and pathogens from drinking water sources have been widely implemented in POU water treatment systems. ${ }^{11,12}$ The removal mechanism of filtration is size exclusion, so that microorganisms larger than the pore size of the filter can be removed from water sources. ${ }^{13,14}$ Particularly, membrane filters with dense porous structures and large surface areas are considered to be one of the most effective POU water treatment processes used in the past decade. ${ }^{15,16}$ For example, mature reverse osmosis (RO) membrane filtration has been used in households for drinking water purification. Owing to their extremely small pore sizes $(<1 \mathrm{~nm})$, RO membranes provide an absolute barrier for microorganisms, keeping them in the water source and preventing waterborne diseases. ${ }^{17}$ However, operating the RO process requires an external driving force such as electrical pumping to achieve the desired flow rate. ${ }^{18,19}$ The requirements of a stable electricity supply and maintenance of RO water treatment systems increase the operation costs, making them impractical for use in developing countries. ${ }^{20,21}$ In addition, biofouling caused by accumulation of microorganisms is still a major challenge for the RO membrane filtration process, which not only decreases the performance of 
the membrane but also shortens its lifespan. ${ }^{22-24}$ Therefore, a low-cost and non-energy-driven membrane filtration system with anti-biofouling activity is considered to be a promising POU water treatment system and highly recommended for people living in rural areas. ${ }^{25-27}$

Compared with RO membranes possessing dense nanopores, microfiltration (MF) membranes with microporous network structure (i.e. cellulose filter paper) have drawn increasing interest as an easy-to-use POU water treatment technology owing to their low cost, high water flux, and nonenergy-driven properties. $^{\text {28-30 }}$ Despite MF membrane-based POU systems being able to remove colloids and suspended solids effectively from drinking water sources, pathogens are hardly blocked at all because of the micropores of MFs. ${ }^{31-33}$ For this reason, the quality of drinking water treated by conventional MF membranes generally fails to meet the drinking water guidelines set by the World Health Organization (WHO), which state that coliforms must not be detected..$^{34-36}$ To address this issue, silver nanoparticles (AgNPs) have been widely used as disinfectants to decorate MF membranes because of their strong and broad-spectrum antibacterial activities. ${ }^{37-39}$ In contrast to conventional MF membranes, these AgNPsdecorated MF membranes can inactivate or kill microorganisms by releasing bactericidal $\mathrm{Ag}^{+}$ions during gravity filtration, resulting in low-cost and efficient POU water disinfection devices to supply safe drinking water. ${ }^{\mathbf{4 0}-\mathbf{4 2}}$ However, the decoration strategies of AgNPs on/in MF membranes mainly depend on noncovalent interactions between membrane substrates and AgNPs, leading to weak immobilization of AgNPs. ${ }^{42-44}$ In most of these cases, the leaching of AgNPs into treated drinking water will be inevitable, which is a potential threat to both humans and the environment. ${ }^{45-47}$ Hence, the robust immobilization of AgNPs onto MF membranes is a primary consideration.

The aim of this work was to immobilize AgNPs on cellulose filter paper (FP) to produce a low-cost POU water disinfection system. In contrast with our previous work, ${ }^{\mathbf{4 0 , 4 5}}$ to realize the robust immobilization of AgNPs onto FP, natural lipoic acidmodified cellulose filter paper (LA-FP) was first prepared through the esterification reaction between the carboxyl group $(-\mathrm{COOH})$ of lipoic acid (LA) and primary alcohol groups $(-\mathrm{OH})$ of $\beta$-glucose units on the filter paper (shown in Scheme 1). ${ }^{\mathbf{4 1 , 4 6}}$ Then, anionic silver nanoparticles (GA@AgNPs) developed in our previous work were anchored onto LA-FP through chelation with the disulfide of LA bond (GA@AgNPs-LA-FP).41,42 The silver loading stability was investigated to determine whether the total leaching of $\mathrm{Ag}^{+}$ions in the treated water met the WHO drinking water standard. Taking advantage of the bacterial anti-adhesion and bactericidal activities of immobilized anionic GA@AgNPs, a GA@AgNPs-LA-FP filter with improved antifouling activity exhibited excellent gravity-driven POU disinfection performance for both model bacteria-contaminated water and natural river water. This study proposes a low-cost, non-energy-driven, and anti-biofouling POU disinfection system to provide safe drinking water for people living in rural areas and prevent waterborne disease.

\section{Experimental}

\subsection{Preparation of silver nanoparticles immobilized cellulose filter paper (GA@AgNPs-LA-FP)}

First, gallic acid-protected silver nanoparticles (GA@AgNPs) were prepared according to our previous work. ${ }^{42,45}$ Then, cellulose filter paper was modified with lipoic acid. Briefly, $0.5 \mathrm{~g}$ of cellulose filter paper and $0.12 \mathrm{~g}$ of lipoic acid $(0.58 \mathrm{mmol})$ were added into $20 \mathrm{~mL}$ dimethyl sulfoxide (DMSO) containing 4dimethylaminopyridine (DMAP; $0.075 \mathrm{~g}, 0.61 \mathrm{mmol}$ ) and $N, N^{\prime}-$ dicyclohexylcarbodiimide (DCC; $0.075 \mathrm{~g}, 0.36 \mathrm{mmol}$ ). After $24 \mathrm{~h}$ reaction under $\mathrm{N}_{2}$ protection at $35{ }^{\circ} \mathrm{C}(90 \mathrm{rpm})$, the cellulose paper was washed with ethanol and dried in vacuo to obtain lipoic acid-modified cellulose paper (LA-FP). Further, the LA-FP samples were then immersed in the GA@AgNPs solution, stirred for $10 \mathrm{~min}$ at room temperature and washed with deionized water to obtain GA@AgNPs immobilized cellulose paper (GA@AgNPs-LA-FP) with a brown color.

\subsection{The silver loading content and the silver loading stability of GA@AgNPs-LA-FP}

An inductively coupled plasma atomic emission spectrometer (model JY38S, France) was used to quantify the silver loading content of GA@AgNPs-LA-FP. Details can be found in the ESI. $\dagger$

\subsection{Antibacterial performance of GA@AgNPs-LA-FP}

The bacterial anti-adhesion and bactericidal abilities of GA@AgNPs-LA-FP were tested using cellulose filter paper as control. Details can be found in the ESI. $\dagger$

Then, a $0.1 \mathrm{~g}$ circular filter paper was rinsed with $0.04 \mathrm{~mL}$ of bacterial solution (containing Escherichia coli and Staphylococcus aureus; $10^{8} \mathrm{CFU} \mathrm{mL}^{-1}$ ), placed in a Petri dish, and incubated at $37^{\circ} \mathrm{C}$ for $24 \mathrm{~h}$. After that, the filter paper specimen was washed with phosphate-buffered saline (PBS) three times. Last, bacterial cells were fixed on the filter paper surface with $3 \%$ glutaraldehyde solution for $4 \mathrm{~h}$ at $4{ }^{\circ} \mathrm{C}$ and treated with different concentrations of ethanol, followed by observation of scanning electron microscopy (SEM). ${ }^{45}$

\subsection{Antifouling property experiments and biofilm characterization}

The filtration biofilm measurements were carried out according to previous work. ${ }^{42}$ First, circles with area $12.56 \mathrm{~cm}^{2}$ were cut from FP and GA@AgNPs-LA-FP and fixed on a filter support. PBS solution $(5 \mathrm{mM})$ with a $\mathrm{pH}$ of 7.4 was used as the medium for bacterial suspension during the filtration. $S$. aureus suspension was diluted in the above medium and cultivated to an $\mathrm{OD}_{600}$ of 0.1 to reach a bacterial concentration of $10^{8} \mathrm{CFU} \mathrm{L}^{-1}$. The mixture was used as the feedwater for the filtration test, and the dynamic biofouling experiments were performed using $2 \mathrm{~L}$ volumes of this feedwater. Before the permeation test, the pristine FP and GA@AgNPs-LA-FP were used to filter the PBS medium solution for $10 \mathrm{~min}$ to obtain initial flux measurements. Then, the permeation tests for GA@AgNPs-LA-FP and FP were performed at room temperature, and the weight increment 


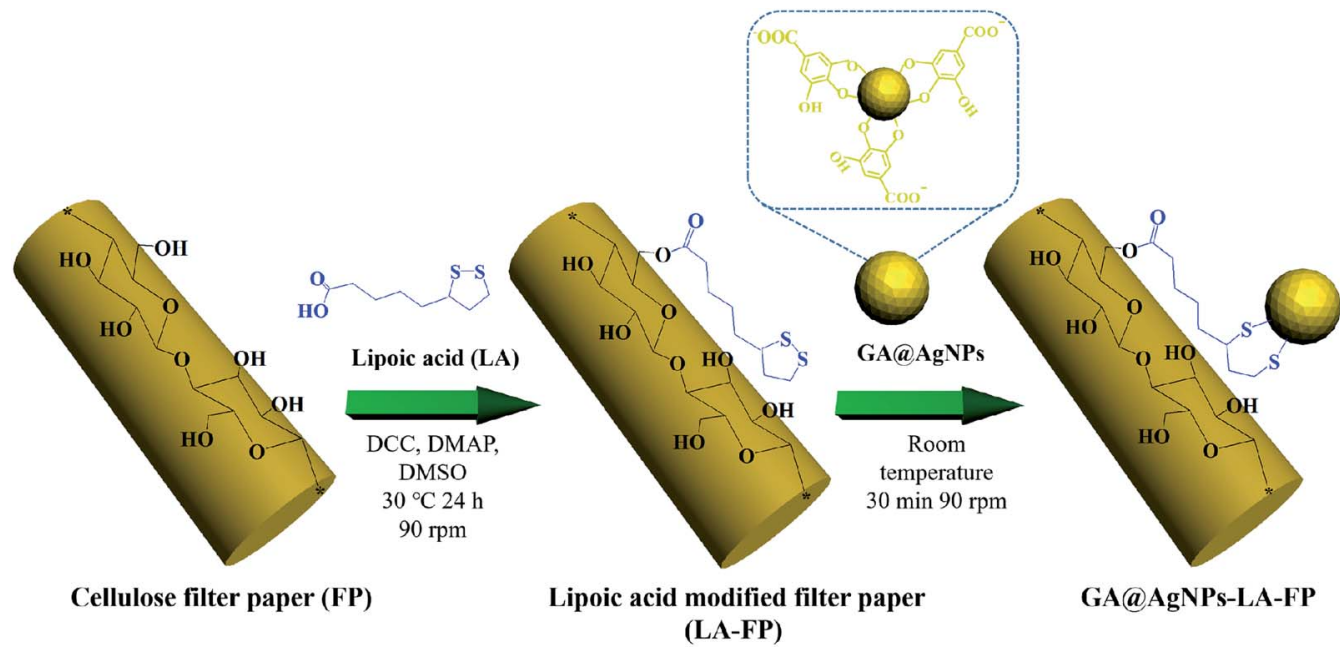

Scheme 1 Schematic illustration of the robust immobilization of GA@AgNPs on lipoic acid-modified filter paper surface.

of filtrate was continuously recorded with time by using an electronic balance (BSM-120.4, Zhuojing, China). ${ }^{21}$ At the end of the biofouling experiment, $1 \mathrm{~cm}^{2}$ of filter paper was cut from the center of the biofouled paper and the biofilm was characterized by SEM.

\subsection{Water disinfection performance of GA@AgNPs-LA-FP}

2.5.1. Disinfection of model contaminated water. Bacterial strains of $E$. coli and $S$. aureus were used as model organisms for water contamination..$^{40} \mathrm{~A} 1 \mathrm{~mL}$ portion of bacteria suspension with a bacterial concentration of $10^{8} \mathrm{CFU} \mathrm{mL}{ }^{-1}$ was diluted to $100 \mathrm{~mL}$ with $99 \mathrm{~mL}$ sterile water, for use as a model of contaminated water. Then, this $100 \mathrm{~mL}$ of contaminated water was passed through GA@AgNPs-LA-FP under gravity. After filtration, $0.02 \mathrm{~mL}$ of the filtrate was collected and dripped on a nutrient agar (NA) plate and cultivated for $24 \mathrm{~h}$ to form bacterial colonies. Bacteria concentrations in contaminated water samples and the filtrate of the filter paper were calculated in the same way. In addition, the filtrate and contaminated water samples were stained using the LIVE/DEAD BacLight ${ }^{\mathrm{TM}}$ bacterial viability kit and observed by confocal laser scattering microscopy (CLSM).

2.5.2. Disinfection of natural river water. Natural contaminated river water samples are complicated: they contain inorganic substances and organic carbon sources, and are turbid, which could have negative impact on a POU water disinfection system. So, the practical disinfection capability of our system was tested by using natural river water samples from the Jinjiang River near Sichuan University in Chengdu, China. A circle of FP or GA@AgNPs-LA-FP with a diameter of $4 \mathrm{~cm}$ was placed in the filter, and then $1 \mathrm{~L}$ of natural river water was passed through the filter paper. During the gravity-driven filtration, the height of the water above GA@AgNPs-LA-FP was maintained at $10 \mathrm{~cm}$ to achieve constant hydraulic pressure. Coliform bacteria are an important indicator of the probable presence of enteric pathogens in drinking water resources, so the coliforms in the natural river water samples were detected by coliform test plates before and after filtration. ${ }^{41}$

\section{Results and discussion}

\subsection{Preparation and characterization of GA@AgNPs-LA-FP}

As depicted in Scheme 1, in order to robustly immobilize silver nanoparticles onto cellulose filter paper (FP), lipoic acid was coupled onto cellulose fiber via the esterification reaction between the carboxyl group $(-\mathrm{COOH})$ of lipoic acid and primary alcohol groups $(-\mathrm{OH})$ of $\beta$-glucose units in the cellulose filter paper. ${ }^{41,46}$ Then, as-prepared GA@AgNPs (seen in Fig. S1†) were stably anchored onto LA-modified filter paper (LA-FP) through strong chelation of the disulfide bond and the surface of silver nanoparticles, forming GA@AgNPs immobilized cellulose filter paper (GA@AgNPs-LA-FP). Compared with pristine FP, which is white in color, the appearance of GA@AgNPs-LA-FP was dark brown, indicating the deposition of AgNPs on the paper surface (photographs in Fig. 1a and b). Moreover, the energy dispersive X-ray spectroscopy (EDS) Ag elemental mapping image of GA@AgNPs-LA-FP in Fig. 1b also demonstrates the successful and uniform deposition of GA@AgNPs. In addition, the SEM images in Fig. 1a and $\mathrm{b}$ show that the introduction of GA@AgNPs onto the paper surface did not affect the network structure of the cellulose filter paper, which suggests that GA@AgNPs-LA-FP can maintain the original performance of pristine filter paper. Further, plenty of tiny white nanoparticles with good dispersion can be observed in the high-magnification SEM image of GA@AgNPs-LA-FP (Fig. 1d). The large silver signal in the EDS spectrum confirmed that these particles were GA@AgNPs. By comparison with the integrated fibrous structure of the fresh filter paper shown in Fig. 1c, the cellulose fibers of GA@AgNPs-LA-FP can be seen to remain undamaged after AgNPs immobilization.

The robust immobilization process of GA@AgNPs on LA-FP was also investigated by X-ray photoelectron spectroscopy (XPS) analysis. As shown in Fig. 2a, only C 1s and $\mathrm{O}$ 1s signals 
FP
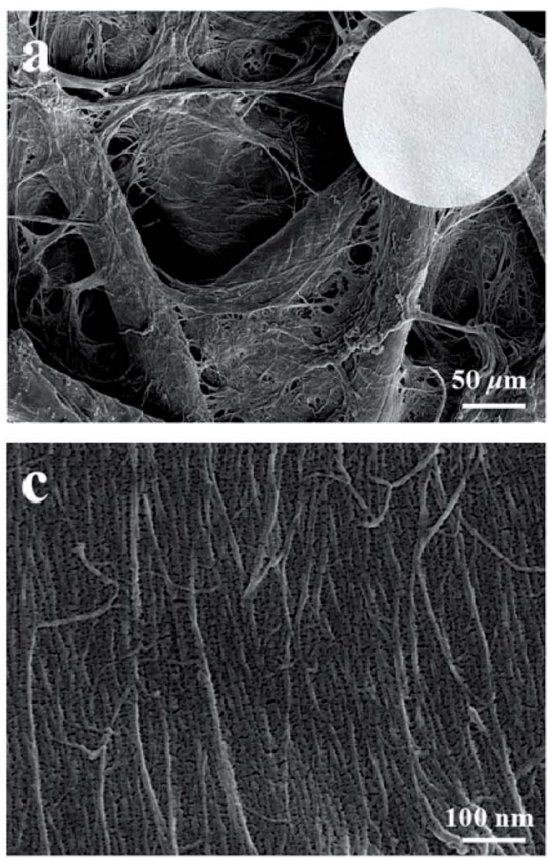

GA@AgNPs-LA-FP
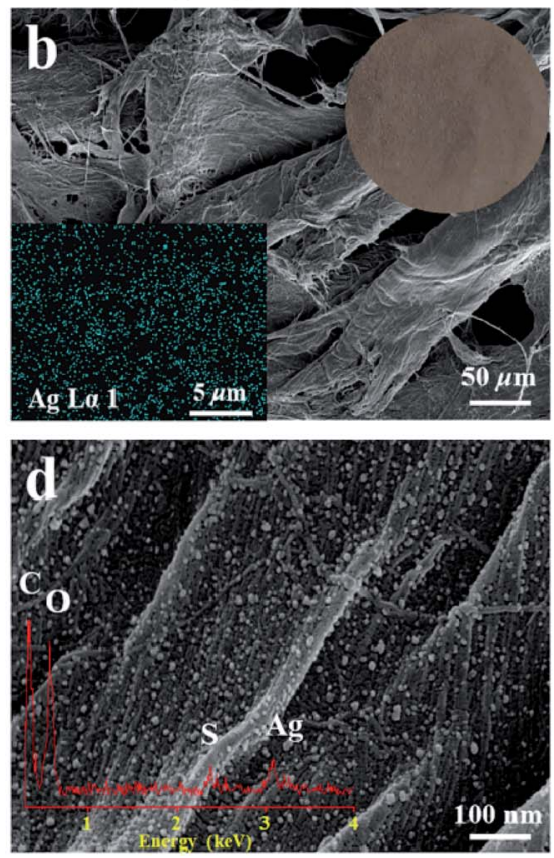

Fig. 1 SEM images of surface morphologies at different magnifications of FP ( $a$ and $c$ ) and GACAgNPs-LA-FP samples (b and d). The inset image in (a) is a photograph of a pristine FP sample. The inset images in (b) are a photograph and EDS-mapping of GA@AgNPs-LA-FP. The inset image in (d) is the EDX spectrum of a GA@AgNPs-LA-FP sample.

were observed from the surface of pristine FP. After grafting lipoic acid, the S $2 \mathrm{p}$ and $\mathrm{S} 2 \mathrm{~s}$ signals assigned to the dithiolane group of lipoic acid were detected for LA-FP (Fig. 2b). Then, the GA@AgNPs deposition was confirmed by the appearance of an $\mathrm{Ag} 3 \mathrm{~d}$ doublet near $372.9 \mathrm{eV}, \mathrm{Ag} 3 \mathrm{p}$ at 578.7 and $609.3 \mathrm{eV}$, and Ag $3 \mathrm{~s}$ at $724.9 \mathrm{eV}$, as shown in Fig. 2c. Moreover, in the Ag 3d corelevel spectrum (Fig. S2 $\dagger$ ), the $6 \mathrm{eV}$ splitting of the $3 \mathrm{~d}$ doublet due to spin-orbit coupling revealed the existence of the $\mathrm{Ag}^{0}$ state on the cellulose filter paper. Further, FP, LA-FP, and GA@AgNPsLA-FP were characterized by high-resolution C 1s XPS to probe the surface functionalization of the paper samples. The deconvolution of C 1s XPS spectra of FP in Fig. 2d contains three peaks at $284.61 \mathrm{eV}, 285.65 \mathrm{eV}$, and $287.22 \mathrm{eV}$, which were assigned to $\mathrm{C}-\mathrm{C}, \mathrm{C}-\mathrm{O}$, and $\mathrm{C}=\mathrm{O}$ bonds in the $\beta$-glucose units of cellulose fibers, respectively. Since cellulose is a natural polymer, its surface may be oxidized, which explains the carbonyl $(\mathrm{C}=\mathrm{O})$ peak at $287.22 \mathrm{eV}$ in the FP sample. In contrast, a new peak at $288.97 \mathrm{eV}$ appeared in the deconvolution of C 1s XPS spectra of LA-FP (Fig. 2e), which was ascribed to $\mathrm{O}-\mathrm{C}=\mathrm{O}$ groups, suggesting esterification reaction between the carboxyl
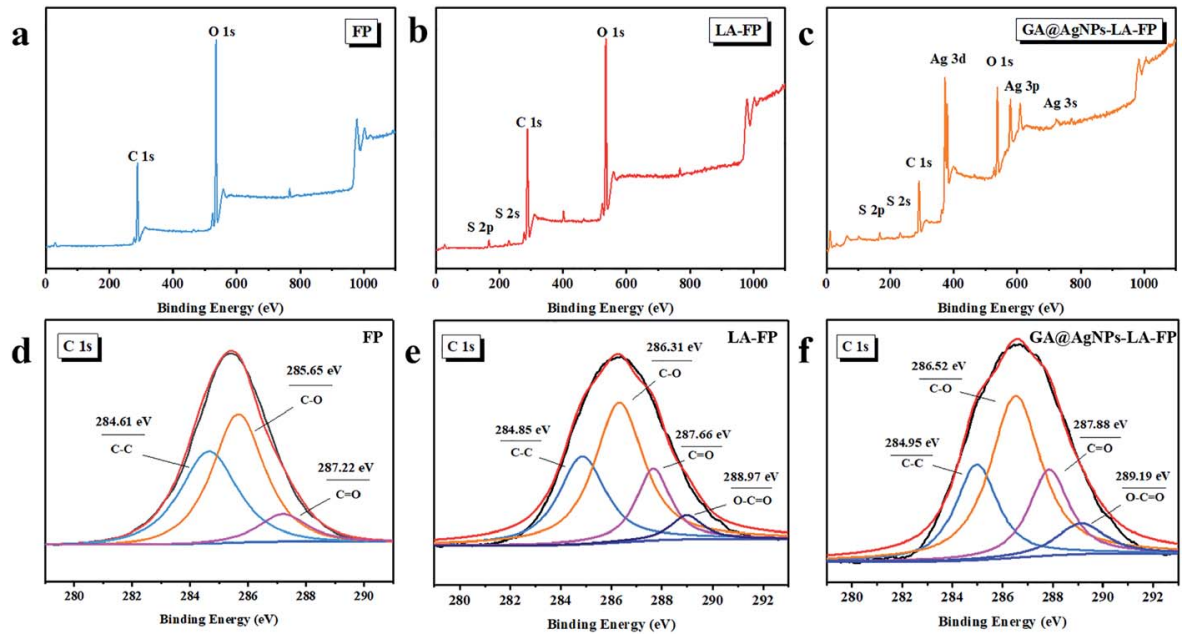

Fig. 2 XPS survey scans of (a) FP, (b) LA-FP and (c) GA@AgNPs-LA-FP; C 1s core-level XPS spectra of (d) FP, (e) LA-FP and (f) GA@AgNPs-LA-FP. 
group of LA and primary alcohol groups of cellulose paper. This result indicates the successful conjugation of LA molecules onto FP. In Fig. 2f, showing the GA@AgNPs-LA-FP sample, the C 1s spectrum was shifted to a higher energy near $286.54 \mathrm{eV}$ owing to the deposition of GA@AgNPs, without the emergence of a new deconvoluted peak; however, the $\mathrm{O}-\mathrm{C}=\mathrm{O}$ bond percentage for GA@AgNPs-LA-FP based on the analysis of the XPS C 1s spectrum was $10.2 \%$, which is higher than the $\mathrm{O}-\mathrm{C}=\mathrm{O}$ bond percentage of $6.7 \%$ for the LA-FP sample (shown in Table S1 $\dagger$ ). This is because the immobilized GA@AgNPs have a high carboxyl group density at their interfaces. Furthermore, the chemical structures of FP, LA-FP, and GA@AgNPs-LA-FP were examined by attenuated total reflection Fourier transform infrared spectroscopy (ATR-FTIR). As shown in Fig. S3, $\dagger$ abundant hydroxyl groups $\left(3326 \mathrm{~cm}^{-1}\right)$ on FP, LA-FP, and GA@AgNPs-LA-FP were observed. The presence of a new peak at $1635 \mathrm{~cm}^{-1}$ was attributed to ester groups on LA-FP, demonstrating the esterification reaction between LA and FP. The new peaks at $1662 \mathrm{~cm}^{-1}$ of GA@AgNPs-LA-FP were attributed to carboxylic groups of GA@AgNPs and ester groups of LA-FP. The above results demonstrate the successful and robust immobilization of GA@AgNPs on the surface of lipoic acid-modified filter paper.

\subsection{Silver loading stability of the GA@AgNPs-LA-FP}

As filtration membrane, the Ag loading content of GA@AgNPsLA-FP was $8.4 \mathrm{mg}$ per gram of cellulose paper, measured by inductively coupled plasma atomic emission spectroscopy (ICPAES). Because of the possible adverse human health effects from silver exposure, the amount of $\mathrm{Ag}$ leached from GA@AgNPs-LA-FP into the effluent water was investigated using a flow-through test to ensure the safety of the drinking water (Fig. 3a). The concentration of silver was about $36 \mu \mathrm{g} \mathrm{L}^{-1}$ in the first $0.1 \mathrm{~L}$ of filtrate. With the increase of permeate volume to $2 \mathrm{~L}$, the silver concentration gradually decreased to $24 \mu \mathrm{g} \mathrm{L}^{-1}$, which meets the US EPA guideline for drinking water $(<100$ ppb), demonstrating the safety of GA@AgNPs-LA-FP for water disinfection. ${ }^{14}$ To prove the non-toxicity of the released $\mathrm{Ag}^{+}$ions, the solution containing released $\mathrm{Ag}^{+}$ions was further used to culture fibroblast L929 cells to test for in vitro cytotoxicity. As shown in Fig. S4, $\uparrow$ there was no statistical difference between the cell viability of L929 cultured in PBS and in the solution containing released $\mathrm{Ag}^{+}$ions. The results demonstrate that the released $\mathrm{Ag}^{+}$ions are non-toxic to normal human cells. In addition, in vitro cytotoxicity of free GA@AgNPs was studied with fibroblast L929 cells. The result revealed low cytotoxicity of the prepared GA@AgNPs (shown in Fig. S5†). Understandably, the results of cytotoxicity tests revealed that GA@AgNPs-LA-FP exhibited no cytotoxicity. Such a low level of silver leaching was mainly attributed to the slow release of $\mathrm{Ag}^{+}$ions from GA@AgNPs robustly chelated to cellulose paper by the disulfide bond of LA. To clarify the silver ion release behavior, GA@AgNPs-LA-FP was immersed in $50 \mathrm{~mL}$ deionized (DI) water and shaken at $150 \mathrm{rpm}$, and the leaching rate of silver was quantified with ICP-AES. As shown in Fig. 3b, the release rate of silver steadily decreased from an initial $2.1 \mu \mathrm{g}$ per day to $1.49 \mu \mathrm{g}$ per day within 5 days. As a result of this relatively low steadystate silver leaching rate, the release of $\mathrm{Ag}$ from the filter paper could be regarded as the leaching of silver ions, rather than leaching of GA@AgNPs from the filter paper. Compared with the total loading content of GA@AgNPs in $50 \mathrm{mg}$ paper $(\sim 420 \mu \mathrm{g})$, the cumulative leaching of $\mathrm{Ag}$ on the $5^{\text {th }}$ day was only 2.15\%, confirming the sustained $\mathrm{Ag}^{+}$release from GA@AgNPsLA-FP. These results indicate that silver nanoparticles were stably loaded onto GA@AgNPs-LA-FP and can potentially provide long-lasting antibacterial activity.

\subsection{Antibacterial activities of GA@AgNPs-LA-FP}

3.3.1. Bacterial anti-adhesion activity. In our previous study, we proved that GA@AgNPs immobilized or incorporated onto solid surfaces can prevent bacterial adhesion through electrostatic repulsion. ${ }^{\mathbf{4 0 , 4 5}}$ Because the high density of anionic carboxyl groups on GA@AgNPs can form a negative interface at neutral $\mathrm{pH}$, it can electrostatically repel bacteria (shown in Fig. 4a). To investigate the effects of the deposition of GA@AgNPs on the surface charge, the surface zeta-potential of GA@AgNPs-LA-FP was analyzed in an aqueous environment at pH 7.0 using pristine filter paper as control. As shown in Fig. 4b, the FP sample presented a negatively-charged surface with a zeta-potential of $17.1 \pm 0.5 \mathrm{mV}$ on account of the many $-\mathrm{OH}$ groups on the cellulose fibers. However, the GA@AgNPs-LA-FP showed an enhanced negative charge $(-23.1 \pm 0.6 \mathrm{mV})$, which
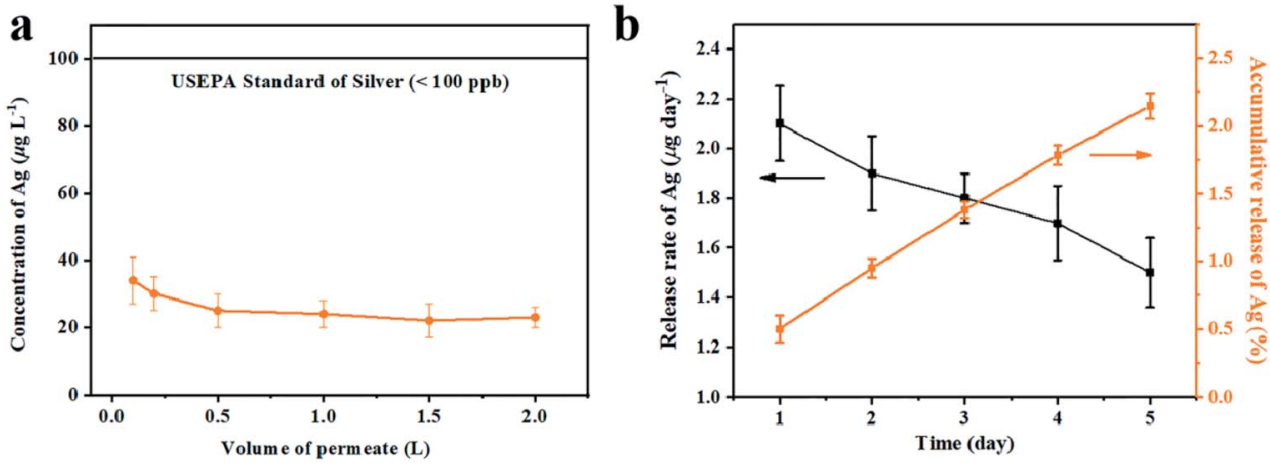

Fig. 3 The release of Ag from GA@AgNPs-LA-FP in the filtration (a) and immersion (b) experiment. 
$\mathbf{a}$
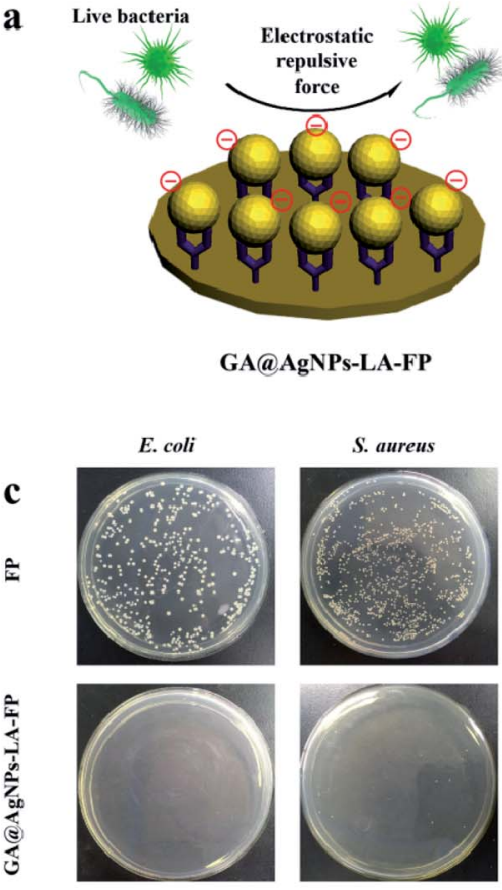

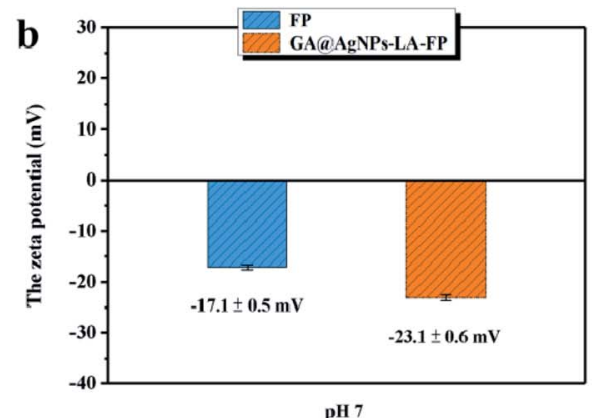

pH 7

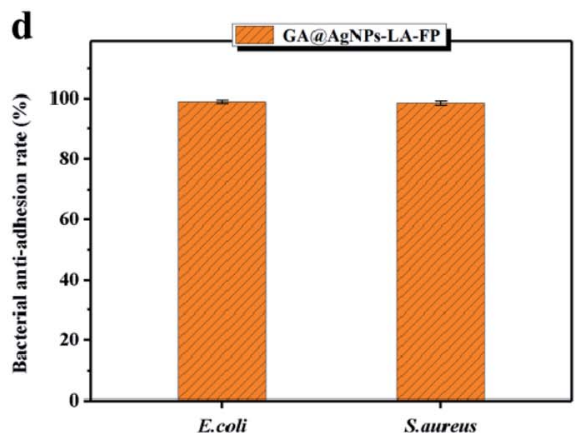

Fig. 4 (a) Schematic of anti-adhesive action of the GA@AgNPs-LA-FP. (b) The surface zeta-potential of the FP and GA@AgNPs-LA-FP at pH 7.0. (c) The corresponding bacterial culture plate photographs, and (d) bacterial anti-adhesion rates of the different samples by plate count method.

was ascribed to the immobilization of GA@AgNPs with many anionic carboxyl groups. The bacterial anti-adhesion activity of GA@AgNPs-LA-FP with an enhanced negative charge was investigated by incubating paper samples with high concentrations $\left(1 \times 10^{8} \mathrm{CFU} \mathrm{mL}{ }^{-1}\right)$ of bacterial suspensions for 4 hours. Afterwards, the bacterial cells attached on the paper surface were separated via ultrasonication and cultivated. Fig. $4 \mathrm{c}$ shows that bacteria easily adhered to the surface of pristine filter paper. On the contrary, almost no viable bacterial cells were observed on the surface of GA@AgNPs-LA-FP, implying effective inhibition of bacterial adhesion via electrostatic repulsion. Moreover, the measurable bacterial antiadhesion rates for the GA@AgNPs-LA-FP sample against $E$. coli and $S$. aureus were $99.5 \%$ and $98.6 \%$, respectively (Fig. 4d). Since bacterial adhesion to a membrane surface is the initial phase before biofilm formation, the excellent bacterial antiadhesion activity of GA@AgNPs-LA-FP is expected to mitigate biofilm formation.

3.3.2. Bactericidal activity. Although the negatively-charged surface of GA@AgNPs-LA-FP can effectively restrain initial biofilm formation by preventing bacterial adhesion, this is just a passive anti-adhesive strategy instead of an active contactkilling property; however, the robust immobilization of GA@AgNPs not only provided an anionic surface but also acted as a reservoir to maintain a continuous contact-killing effect via the persistent release of silver ions into the surrounding environment. To understand the AgNPs-decorated antibacterial surface, the morphology of bacterial cells in contact with FP and GA@AgNPs-LA-FP were investigated by SEM. Compared with the viable bacteria with intact cell membranes seen on the FP surface, distinct damage was observed on the cell membranes of both bacterial strains on GA@AgNPs-LA-FP (Fig. 5b). This demonstrates the contact-killing ability of immobilized AgNPs. Further, this contact-killing bactericidal activity of GA@AgNPsLA-FP was tested by the CFU counting method. As presented in Fig. $5 \mathrm{~b}$, the numbers of attached live E. coli and $S$. aureus on GA@AgNPs-LA-FP decreased by $99.3 \pm 0.4 \%$ and $98.8 \pm 0.7 \%$, respectively, compared with the FP. These CFU results confirm the outstanding bactericidal properties of GA@AgNPs-LA-FP due to the $\mathrm{Ag}^{+}$ion-mediated killing mechanism. Considering the negatively-charged surface and long-term release profile of immobilized GA@AgNPs, GA@AgNPs-LA-FP is expected to show long-term antibacterial activity to mitigate membrane biofouling during its application as a POU water disinfection device.

3.3.3. Anti-biofouling activity. The biofouling that usually occurs on filter membranes has been a dominant barrier limiting the application of membranes in water treatment, owing to declining rate of flow and shortened working life. ${ }^{47,48}$ In Fig. 6a, a gradual and persistent decrease in the permeate rate of water flow due to biofilm was calculated for both FP and GA@AgNPs-LA-FP. ${ }^{51,52}$ The rate of water flow with FP declined by about $58 \%$ after the filtration process. On the contrary, the decrease in the rate of flow for the GA@AgNPs-LA-FP was only $20 \%$, indicating the anti-biofouling due to the synergy between anti-adhesion and antibacterial activities of immobilized GA@AgNPs. After filtration, FP and GA@AgNPs-LA-FP were further analyzed by SEM, which showed that a biofilm containing many $S$. aureus cells formed on the FP surface (shown in Fig. 6b); in contrast, scarcely any viable bacterial cells were seen 

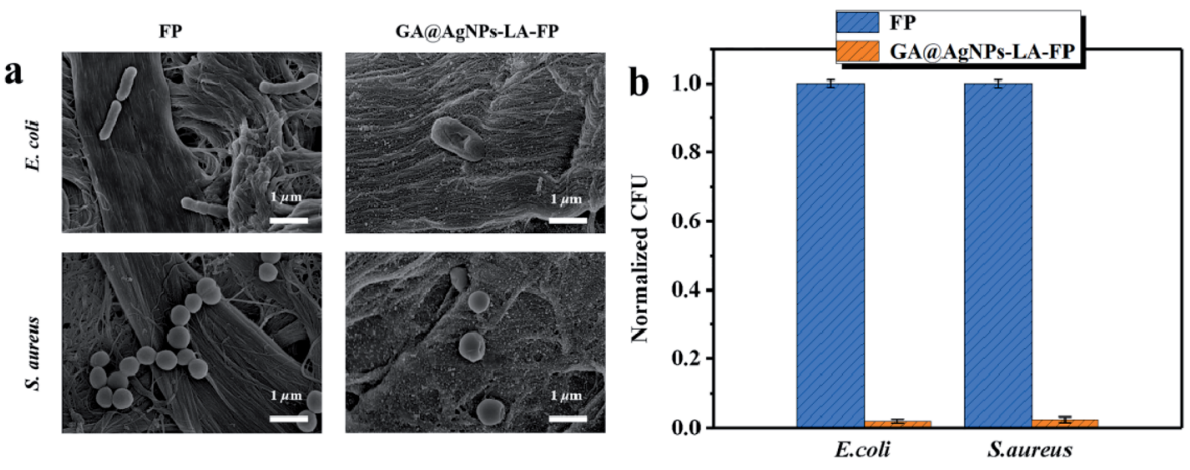

Fig. 5 (a) SEM images of E. coli and S. aureus cells in contact with the FP and GA@AgNPs-LA-FP. (b) Antibacterial efficiency of the different samples by plate count method. The antibacterial activity was expressed as normalized colony-forming units (CFU) relative to the pristine FP control.

on the surface of GA@AgNPs-LA-FP. The confocal laser scanning microscopy (CLSM) and field emission scanning electron microscopy (FESEM) images in Fig. S6 and S7 $\dagger$ clearly demonstrate the biofilms on GA@AgNPs-LA-FP were composed of more dead cells with fewer live cells than biofilms formed on FP. This result provides solid evidence that GA@AgNPs-LA-FP can mitigate biofouling by inhibiting biofilm formation and thus greatly reducing a decline in water flux during operation.

\subsection{Point-of-use water disinfection performance of GA@AgNPs-LA-FP during gravity-driven filtration}

3.4.1. Disinfection of model contaminated water. To evaluate the water disinfection activity of GA@AgNPs-LA-FP, $100 \mathrm{~mL}$ of $E$. coli or $S$. aureus aqueous suspensions with concentrations of $1 \times 10^{6} \mathrm{CFU} \mathrm{mL}{ }^{-1}$ were prepared as the model bacteriacontaminated feedwater. ${ }^{49,50}$ As a proof of concept, a water disinfection test was performed by direct filtration under gravity, as shown in Fig. 7a. The average flow rate of bacterial suspensions through the filter paper was about $480 \mathrm{~L} \mathrm{~m}^{-2} \mathrm{~h}^{-1}$, via controlling the water height above the filter at $5 \mathrm{~cm}$ to maintain hydraulic pressure. Before filtration, merged CLSM images show a large of number of live bacteria cells stained with Live/Dead stains in the initial feed solution (Fig. 7b). In contrast, almost all bacteria cells in treated water filtered by GA@AgNPs-LA-FP were dead, indicating that the bacteria in the initial feed solution were effectively contact-killed by the immobilized GA@AgNPs during filtration. To further verify the water disinfection capacity of GA@AgNPs-LA-FP, viable bacteria in the effluent water were cultured on agar medium for $12 \mathrm{~h}$, and bacterial colonies were counted, using bacteriacontaminated feedwater treated using pristine filter paper (FP) as a control. As shown in Fig. 7c, the FP sample with no antibacterial activity exhibited a minor filtration effect for bacteria, with a log reduction lower than 1.0. This low bacteria reduction was attributed to the microporous structure of pristine filter paper (shown in Fig. 1a), which failed to effectively filter bacteria because it only acted as a physical barrier to remove very limited bacteria in the filtration process.

This result confirms the continuous bactericidal activity of GA@AgNPs-LA-FP in the effluent by the sustained release of silver ions. Moreover, it is noted that the bacterial reduction after filtration through the GA@AgNPs-LA-FP was more than 5

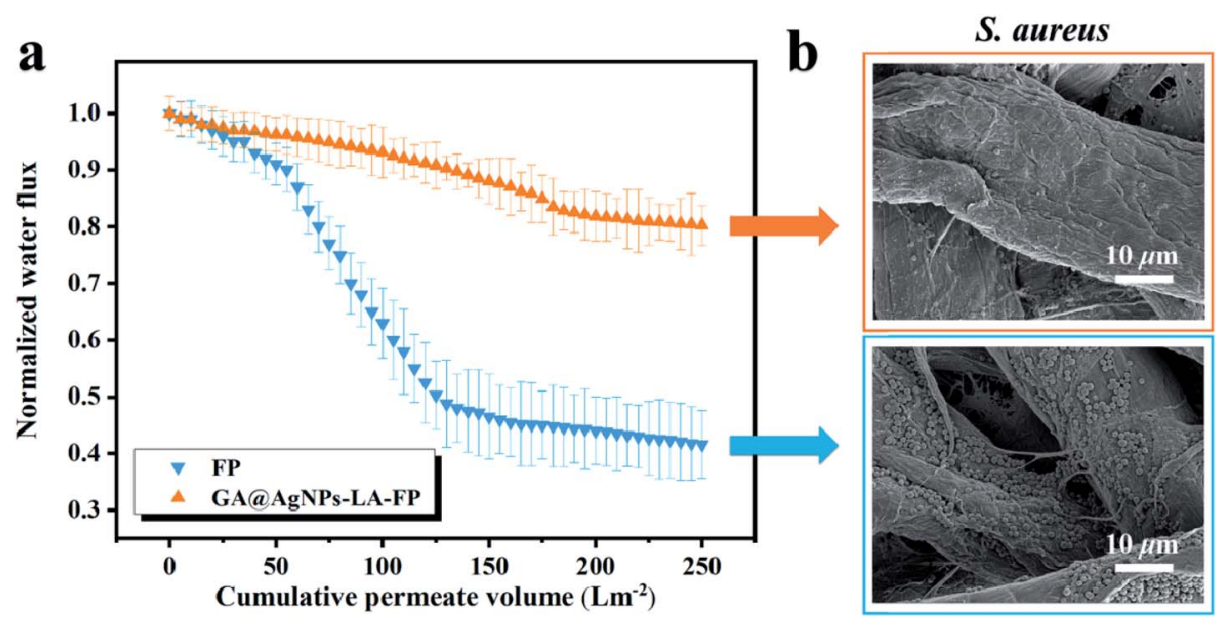

Fig. 6 (a) Normalized water flux of FP and GA@AgNPs-LA-FP samples as a function of the cumulative permeate flux in the dynamic biofouling experiment using S. aureus. (b) SEM images of $S$. aureus cells on FP and GA@AgNPs-LA-FP after filtration. 

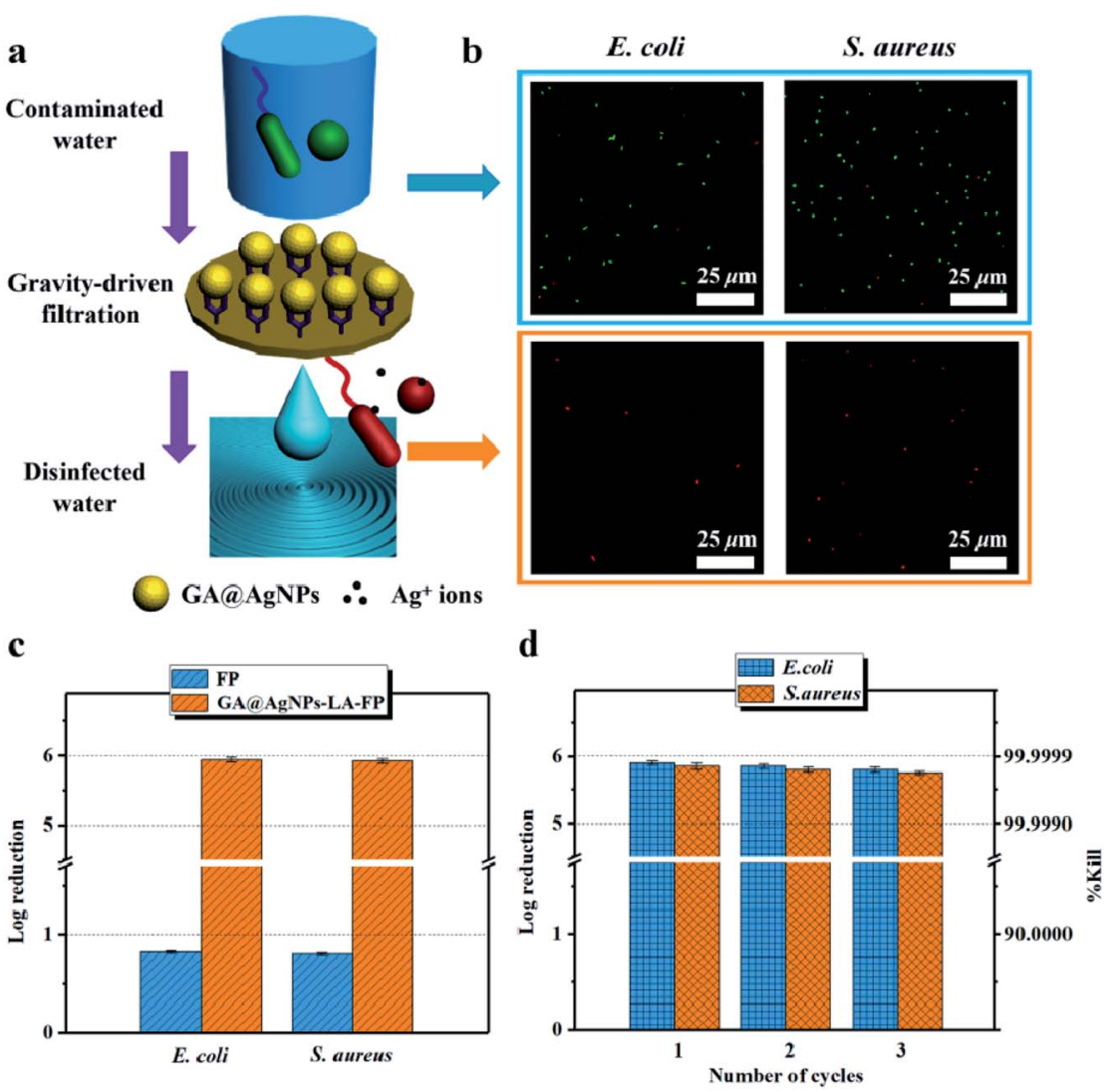

Fig. 7 (a) Schematic POU water disinfection performance of GA@AgNPs-LA-FP. (b) CLSM images of E. coli and S. aureus cells stained by the Live/ Dead kit before and after permeation through GA@AgNPs-LA-FP. (c) Log reduction of $E$. coli and $S$. aureus bacterial count after permeation through FP and GA@AgNPs-LA-FP. (d) Cyclic water disinfection activities of GA@AgNPs-LA-FP against E. coli and S. aureus solution.

orders of magnitude higher than the control, and meets the US EPA standard for a water purification device. Further, the cyclic water disinfection activity was evaluated by repeatedly filtering $100 \mathrm{~mL}$ samples of bacterial solution through GA@AgNPs-LAFP. After filtration of the first $100 \mathrm{~mL}$ sample, the bacterial reduction was measured and set as one cycle. For this test, another three cycles were carried out. As shown in Fig. 7d, even after 3 cycles, the GA@AgNPs-LA-FP still retained satisfactory antibacterial activities, with a log reduction higher than 5.0. This indicates that the active bactericidal effect provided by robust immobilized AgNPs was not abrogated by a covering of dead bacterial cells because of the passive anti-adhesion activity offered by the negatively-charged GA@AgNPs interface; therefore, GA@AgNPs-LA-FP can provide long-term water disinfection performance.

3.4.2. Disinfection of natural river water. GA@AgNPs-LAFP was also used to disinfect natural river water to investigate its practical disinfection application for drinking water resources. Fig. 8a shows the contaminated river water sample for the POU disinfection test, which was turbid because of its complex composition, including organic microorganisms, inorganic substances, and so on. Within $10 \mathrm{~min}, 0.1 \mathrm{~L}$ of the river water sample was filtered through a circular GA@AgNPsLA-FP sample. On filtration, the turbid river water became clear (shown in Fig. 8a) because of the porous network structure of cellulose filter paper, which physically removed suspended solids in the natural water. After that, $0.1 \mathrm{~mL}$ samples of both untreated and disinfected water were cultivated on agar plates and standard coliform test plates for $24 \mathrm{~h}$ to count their respective colony-forming units. Clearly, for the untreated water sample, lots of colonies grew both on the agar plate and on the standard coliform test plate (seen in Fig. 8b). The total concentrations of viable bacteria and coliforms in contaminated river water, summarized in Table $\mathrm{S} 2, \dagger$ were $2.1 \times 10^{3} \mathrm{CFU}$ $\mathrm{mL}^{-1}$ and $1.5 \times 10^{4} \mathrm{MPN} / 100 \mathrm{~mL} .{ }^{37}$ After filtration, no bacterial colonies on the agar plate or standard coliform test plate were observed for the treated water, implying nearly all bacteria were inactivated by GA@AgNPs-LA-FP. Table S2† shows that the average concentration of viable bacteria in filtered water samples treated with GA@AgNPs-LA-FP was only 11.0 CFU $\mathrm{mL}^{-1}$, which is far below the WHO requirement for drinking

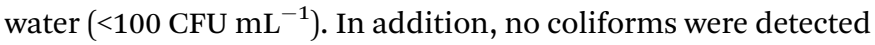
in the treated water. The inactivation rates for GA@AgNPs-LAFP against total live bacteria and coliforms were $99.5 \%$ and $100 \%$, respectively; however, for the water sample treated with $\mathrm{FP}$, the total live bacteria concentration and coliform bacteria were $5.1 \times 10^{2} \mathrm{CFU} \mathrm{mL}{ }^{-1}$ and $5.3 \times 10^{3} \mathrm{MPN} / 100 \mathrm{~mL}$. Although some of the bacteria in raw water were physically removed by FP, the quality of the filtered water was not up to the standard 

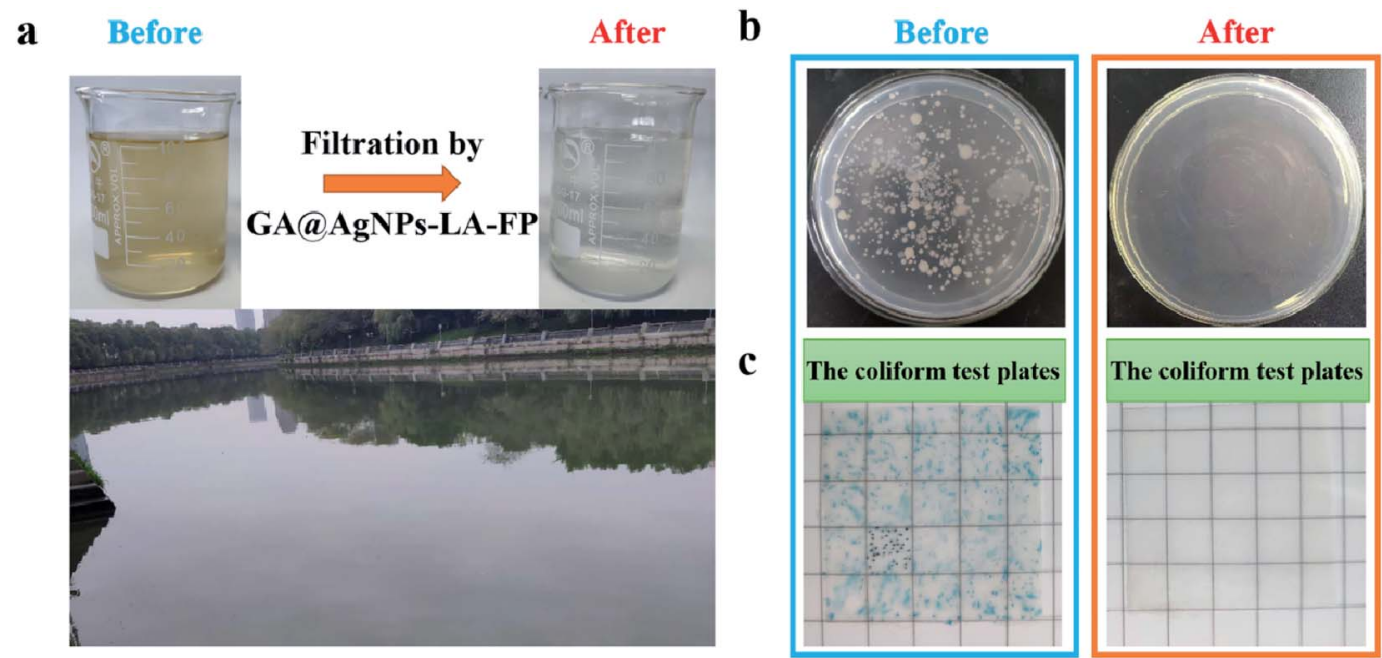

Fig. 8 (a) Photographs of appearance of natural river water before and after treatment with GA@AgNPs-LA-FP. (b) Growth of bacterial colonies on agar plates and standard coliform test plates from natural river water before and after filtration.

for drinking water (total bacteria $<100 \mathrm{CFU} \mathrm{mL}^{-1}$, no coliforms). ${ }^{14}$

To test the reusability of GA@AgNPs-LA-FP for effective POU water disinfection, $1 \mathrm{~L}$ of contaminated natural river water was filtered by GA@AgNPs-LA-FP in $100 \mathrm{~min}$, and the number of bacteria was counted for each $0.2 \mathrm{~L}$ of output. The results indicated that the overall live bacteria concentration was less than $15 \mathrm{CFU} \mathrm{mL}{ }^{-1}$ after treatment, and no coliforms were found (Fig. S8 $\dagger$ ), which showed that GA@AgNPs-LA-FP had good stability for effective POU water disinfection application. Moreover, using a $10 \times 10 \mathrm{~cm}^{2}$ GA@AgNPs-LA-FP sample, $2 \mathrm{~L}$ of purified clean drinking water was collected within approximately $25 \mathrm{~min}$, which meets the needs of an adult for one day. These results demonstrate the good application prospects for POU water disinfection in remote rural areas or under emergency conditions.

\section{Conclusions}

A low-cost GA@AgNPs-LA-FP filter was successfully fabricated with robust immobilization of anionic silver nanoparticles onto lipoic acid-modified cellulose filter paper via strong chelation between LA disulfide bonds and silver nanoparticles. As a result of the negatively-charged interface and sustained $\mathrm{Ag}^{+}$leaching from immobilized GA@AgNPs, this GA@AgNPs-LA-FP showed both excellent anti-adhesion and strong antibacterial activities, which could synergistically inhibit biofilm formation on the paper surface. In addition, the amount of silver leached from GA@AgNPs-LA-FP was below the WHO drinking water standard for $\mathrm{Ag}^{+}$, which verifies that it can be used as a safe water disinfection system. As a novel antibacterial filter, the water disinfection property of GA@AgNPs-LA-FP was evaluated by using it to treat $100 \mathrm{~mL}$ of bacterial aqueous suspensions containing concentrations of $1 \times 10^{6} \mathrm{CFU} \mathrm{mL}^{-1}$, with a hydraulic retention time of $10 \mathrm{~min}$ via gravity filtration. The results showed that the bacterial reduction after filtration was more than 5 orders of magnitude higher than the control, and meets the US EPA standards for a water purification device. Moreover, the potential application of GA@AgNPs-LA-FP for POU water disinfection was also tested using natural river water. The results revealed that almost all live bacteria in the contaminated river water were inactivated when passed through GA@AgNPsLA-FP via gravity filtration within $100 \mathrm{~min}$, demonstrating the paper's viability for practical POU water disinfection.

\section{Conflicts of interest}

There are no conflicts to declare.

\section{Acknowledgements}

This work was supported by the support program of Chengdu Science and Technology Bureau (2019-GH02-00001-HZ), opening project of State Key Laboratory of Hydraulics and Mountain River Engineering, Sichuan University (SKHL1816), opening project of laboratory and equipment management, Sichuan University (SCU 203031), and opening project of Key Laboratory of Leather Chemistry and Engineering of Ministry of Education, Sichuan University (20826041C4159).

\section{Notes and references}

1 M. A. Shannon, P. W. Bohn, M. Elimelech, J. G. Georgiadis, B. J. Marinas and A. M. Mayes, Nature, 2008, 452, 301-310.

2 A. Prabhakar, M. Agrawal, N. Mishra, N. Roy, A. Jaiswar, A. Dhwaja and D. Verma, RSC Adv., 2020, 10, 17479-17485.

3 M. S. Mauter, I. Zucker, F. O. Perreault, J. R. Werber, J. H. Kim and M. Elimelech, Nat. Sustain., 2018, 1, 166-175. 4 K. P. Ching and Y. N. How, npj Clean Water, 2018, 11, 1-8.

5 H. Zhao, L. Yang, Y. Li, W. Xue, K. Li, Y. Xie, S. Meng and G. Cao, RSC Adv., 2020, 10, 28267-28276. 
6 P. J. J. Alvarez, C. K. Chan, M. Elimelech, N. J. Halas and D. Villagran, Nat. Nanotechnol., 2018, 13, 634-641.

7 Z. Zhu, L. Shan, F. Hu, Z. Li, D. Zhong, Y. Yu and J. Zhang, $R S C A d v .$, 2020, 10, 31295-31304.

8 D. H. Seo, S. Pineda, Y. C. Woo, M. Xie, A. T. Murdock, E. Y. M. Ang, Y. Jiao, M. J. Park, S. I. Lim, M. Lawn, F. F. Borghi, Z. J. Han, S. Gray, G. Millar, A. Du, H. K. Shon, T. Y. Ng and K. K. Ostrikov, Nat. Commun., 2018, 9, 683.

9 I. B. Gomes, L. C. Simões and M. Simões, $R S C$ Adv., 2019, 9, 32184-32196.

10 K. L. Kotloff, Lancet, 2013, 382, 209-222.

11 S. Ghosh, S. Das and M. E. G. Mosquera, Polymers, 2020, 12, 2993.

12 F. Wang, J. Dai, L. Huang, Y. Si, J. Yu and B. Ding, ACS Nano, 2020, 14, 8975-8984.

13 Y. Si, J. Y. Li, C. Y. Zhao, Y. Deng, Y. Ma, D. Wang and G. Sun, ACS Biomater. Sci. Eng., 2017, 3, 854-862.

14 M. Fan, L. Gong, J. Sun, D. Wang, F. Bi and Z. Gong, ACS Appl. Mater. Interfaces, 2018, 10, 38239-38245.

15 T. F. Clasen, I. G. Roberts, T. Rabie, W. P. Schmidt and S. Cairncross, Br. Med. J., 2006, 334, 782-785.

16 J. Zhu, J. Hou, Y. Zhang, M. Tianb, T. Hee, J. Liu and V. Chen, J. Membr. Sci., 2018, 550, 173-197.

17 S. Ghosh, G. Amariei, M. E. G. Mosquera and R. Rosal, J. Hazard. Mater., 2021, 402, 123788.

18 X. Zhang, Z. Wang, C. Y. Tang, J. Ma, M. Liu, M. Ping, M. Chen and Z. Wu, J. Membr. Sci., 2018, 549, 165-172.

19 Y. Gu, G. Teng, X. Jin, L. Wang, Z. Qiang, W. Ma and C. Zhang, Ind. Eng. Chem. Res., 2020, 59, 11219-11231.

20 S. Ghosh, P. Chakraborty, A. Chakrabarti, M. Ghosh, A. Mandal, P. Saha, A. Mukherje, S. Acharya and M. Ray, RSC Adv., 2016, 6, 6631.

21 W. B. Zhao, M. R. Du, K. K. Liu, R. Zhou, R. N. Ma, Z. Jiao, Q. Zhao and C. X. Shan, ACS Appl. Mater. Interfaces, 2020, 12, 13305-13315.

22 S. Ghosh, S. R. Keshri, S. Bera and R. N. Basu, Int. J. Hydrogen Energy, 2020, 45, 6159-6173.

23 D. Li, Y. Yan and H. Wang, Prog. Polym. Sci., 2016, 61, 104155.

24 L. Malaeb and G. M. Ayoub, Desalination, 2011, 267, 1-8.

25 G. Kang and Y. Cao, Water Res., 2012, 46, 584-600.

26 D. L. Shaffer, J. R. Werber, H. Jaramillo, S. H. Lin and M. Elimelech, Desalination, 2015, 356, 271-284.

27 M. Elimelech and W. A. Phillip, Science, 2011, 333, 712-717. 28 S. Bera, S. Ghosh and R. N. Basu, J. Alloys Compd., 2020, 830, 154527.

29 J. M. Daniel, R. D. Daniel, W. B. Christopher, R. P. Donald and D. F. Benny, Angew. Chem., Int. Ed., 2017, 56, 4662-4711.
30 R. Zhang, Y. Liu, M. He, Y. Su, X. Zhao, M. Elimelechc and Z. Jiang, Chem. Soc. Rev., 2016, 45, 5888-5924.

31 J. Wang, M. Sui, Z. Ma, H. Li and B. Yuan, $R S C$ Adv., 2019, 9, 25667-25676.

32 A. Zirehpour, A. Rahimpour, A. A. Shamsabadi, M. G. Sharifian and M. Soroush, Environ. Sci. Technol., 2017, 51, 5511-5522.

33 C. S. Ong, P. S. Goh, W. J. Lau, N. Misdan and A. F. Ismail, Desalination, 2016, 393, 2-15.

34 T. S. Kim, S. H. Park, D. Parka, J. H. Lee and S. Kanga, J. Membr. Sci., 2019, 576, 17-25.

35 S. Xiong, S. Xu, A. Phommachanh, M. Yi and Y. Wang, Environ. Sci. Technol., 2019, 53, 3331-3341.

36 S. M. Praveena, K. Karuppiah and L. T. L. Than, Cellulose, 2018, 25, 2647-2658.

37 X. Zeng, D. T. McCarthy, A. Deletic and X. Zhang, Adv. Funct. Mater., 2015, 25, 4344-4351.

38 T. A. Dankovich and D. G. Gray, Environ. Sci. Technol., 2011, 45, 1992-1998.

39 J. Wang, Y. Wu, Z. Yang, H. Guo, B. Cao and C. Y. Tang, Sci. Rep., 2018, 7, 1-8.

40 G. Liu, J. Jiang, R. Yu, H. Yan and R. Liang, Ind. Eng. Chem. Res., 2020, 59, 10857-10867.

41 Y. L. Li, L. Zhu, Z. Liu, R. Cheng, F. Meng, J. H. Cui, S. J. Ji and Z. Zhong, Angew. Chem., 2009, 121, 10098-10102.

42 G. Liu, H. Gao, K. Li, T. Lan and Z. Zhang, J. Colloid Interface Sci., 2017, 514, 338-348.

43 T. Lan, R. An, Z. Liu, K. Li, J. Xiang and G. Liu, J. Colloid Interface Sci., 2018, 532, 331-342.

44 P. V. Cherepanov, M. A. Rahim, N. Bertleff-Zieschang, M. Abu Sayeed, A. P. O'Mullane, S. E. Moulton and F. Caruso, ACS Appl. Mater. Interfaces, 2018, 10, 5828-5834.

45 Q. Xia, L. Yang, K. Hu, K. Li, J. Xiang, G. Liu and Y. Wang, ACS Appl. Mater. Interfaces, 2019, 11, 2352-2363.

46 M. S. Islam, N. Akter, M. M. Rahman, C. Shi, M. T. Islam, H. Zeng and M. S. Azam, ACS Sustainable Chem. Eng., 2018, 6, 9178-9188.

47 B. S. Moshe, R. Z. Katherine, G. G. Qi, K. Yan, E. P. Giannelis and M. Elimelech, Environ. Sci. Technol., 2014, 48, 384-393.

48 F. Perreault, H. Jaramillo, M. Xie, U. Mercy, L. D. Nghiem and M. Elimelech, Environ. Sci. Technol., 2016, 50, 58405848.

49 L. Qi, Y. Hu, Z. Liu, X. An and E. Bar-Zeev, Environ. Sci. Technol., 2018, 52, 9684-9693.

50 S. M. Praveena, L. S. Han, L. T. L. Than and A. Z. Aris, J. Exp. Nanosci., 2016, 11, 1307-1319.

51 L. Qi, Z. Liu, N. Wang and Y. Hu, Appl. Surf. Sci., 2018, 456, 95-103.

52 S. A. Aani, V. Gome, C. J. Wright and N. Hilal, Chem. Eng. J., 2017, 326, 721-736. 